\title{
Phytophthora infestans Has a Plethora of Phospholipase D Enzymes Including a Subclass That Has Extracellular Activity
}

\author{
Harold J. G. Meijer ${ }^{1 *}$, Hussen Harrun Hassen ${ }^{10}$, Francine Govers ${ }^{1,2}$ \\ 1 Laboratory of Phytopathology, Plant Sciences Group, Wageningen University, Wageningen, The Netherlands, 2 Centre for BioSystems Genomics (CBSG), Wageningen, \\ The Netherlands
}

\begin{abstract}
In eukaryotes phospholipase D (PLD) is involved in many cellular processes. Currently little is known about PLDs in oomycetes. Here we report that the oomycete plant pathogen Phytophthora infestans has a large repertoire of PLDs divided over six subfamilies: PXPH-PLD, PXTM-PLD, TM-PLD, PLD-likes, and type A and B SPLD-likes. Since the latter have signal peptides we developed a method using metabolically labelled phospholipids to monitor if $P$. infestans secretes PLD. In extracellular medium of ten $P$. infestans strains PLD activity was detected as demonstrated by the production of phosphatidic acid and the PLD specific marker phosphatidylalcohol.
\end{abstract}

Citation: Meijer HJG, Hassen HH, Govers F (2011) Phytophthora infestans Has a Plethora of Phospholipase D Enzymes Including a Subclass That Has Extracellular Activity. PLoS ONE 6(3): e17767. doi:10.1371/journal.pone.0017767

Editor: Jonathan Badger, J. Craig Venter Institute, United States of America

Received January 6, 2011; Accepted February 14, 2011; Published March 14, 2011

Copyright: () 2011 Meijer et al. This is an open-access article distributed under the terms of the Creative Commons Attribution License, which permits unrestricted use, distribution, and reproduction in any medium, provided the original author and source are credited.

Funding: This research was supported by the Dutch Technology Foundation STW, applied science division of NWO, and the Technology Programme of the Ministry of Economic Affairs, in the framework of a VIDI project (HM) and by the Centre for BioSystems Genomics (CBSG) which is part of the Netherlands Genomics Initiative/Netherlands Organization for Scientific Research (FG). The funders had no role in study design, data collection and analysis, decision to publish, or preparation of the manuscript.

Competing Interests: The authors have declared that no competing interests exist.

* E-mail: Harold.Meijer@wur.nl

a Current address: Melkassa Agricultural Research Centre, Ethiopian Institute of Agricultural Research, Nazareth, Ethiopia

\section{Introduction}

In eukaryotes, phospholipid-based signalling and metabolism play important roles in numerous cellular processes. Phospholipids are ubiquitous components of all cell membranes and, as second messengers, they act as modulators of many cellular functions. Conversion of phospholipids is accomplished by enzymes that are well conserved across eukaryotes and play crucial roles in cellular regulation, metabolism, stress responses and phospholipid biosynthesis. Important classes of phospholipid modifying enzymes are phospholipid kinases, phospholipid phosphatases and phospholipases. The latter are a heterogeneous group of enzymes whose classification is based on their catalytic activity and substrate specificity.

Phospholipase D (PLD) catalyzes the hydrolysis of structural phospholipids at their terminal phosphoesteric bond, leading to the production of a hydrophilic constituent and phosphatidic acid (PA). The latter has emerged as a significant lipid mediator in many cellular processes. PA mediated signal transduction includes modulation of receptor signalling, cytoskeleton rearrangement, secretion, and vesicle trafficking during endocytosis or exocytosis [1]. All eukaryotes have PXPH-PLDs that are composed of the N-terminally located phosphoinositide binding domains Pleckstrin homology $(\mathrm{PH})$ and PHOX homology $(\mathrm{PX})$. These precede the catalytic site and regulatory motifs. Unique to plants are the C2$\mathrm{PLDs}$ that contain the $\mathrm{N}$-terminally located calcium/lipid binding domain C2. These two PLD subfamilies have a catalytic site with two highly conserved motifs each consisting of $\mathrm{HxK} \times \mathrm{xxxD}$ (hereafter HKD1 and HKD2). Bacteria have PLDs that harbour the catalytic site and regulatory motifs but lack phosphoinositide binding domains. Also "non-HKD-PLDs" have been identified, enzymes with PLD activity but lacking characteristic motifs [2]. Recently, a novel rice (Oryza sativa) PLD was described that contains the two HKD motifs as well as a N-terminal signal peptide (SP) [3].

Annotation of the genomes of Phytophthora sojae and Phytophthora ramorum revealed that Phytophthora has a variable set of PLD genes. Phytophthora lacks C2-PLD genes but possesses one PXPH-PLD gene. In addition, there are seventeen PLD genes that represent novel subfamilies including a subfamily with SP sequences that encodes potentially secreted PLDs [4]. In this study we performed an in depth analysis of the PLD subfamilies in Phytophthora infestans, the causal agent of potato late blight and the most notorious Phytophthora species. All Phytophthora PLD subfamilies were detected but the subfamily of PLDs with SPs (sPLD-likes) appears to be comprised of two unrelated subfamilies, sPLD-like-A and sPLDlike-B. Moreover, we developed a method that makes use of reconstituted plant membrane vesicles for analysing the presence of PLD activity in extracellular medium of $P$. infestans and provide evidence that $P$. infestans indeed secretes PLD. This finding points to a putative role for PLD in pathogenicity.

\section{Materials and Methods}

\section{Bioinformatic analysis}

Putative PLD genes in the P. infestans genome database of strain T304 (http://www.broad.mit.edu/annotation/genome/phytophthora_ infestans) were identified by several methods including automatic 
annotation, BLAST searches with the $P$. sojae and $P$. ramorum PLD gene models [4], and with representative PLD sequences from NCBI GenBank. Putative PLD gene models were further analysed based on characteristic conserved motifs and manually corrected when needed. Multiple alignments were made in ClustallW2. Phylograms were constructed by Mega4.1 using the Minimum Evolution method with a bootstrap test based on 5000 replicates, and the Poisson correction method [5]. Signal and anchor peptides were detected via SignalP 3.0 (http://www.cbs.dtu.dk/services/SignalP/) using default parameters. Putative transmembrane domains were analysed as described before [6]. Searches for additional proteins domains were performed via publically available databases. For determining synteny between Phytophthora spp. gene models present in regions flanking PLD genes were extracted and used for reciprocal BLAST analysis. Pairs of genes sharing best reciprocal BLAST hits were assigned as orthologues. Intergenic lengths were determined by taking the distance between the
PLD gene and the neighbouring gene model thereby ignoring mobile elements.

\section{Phytophthora infestans culture condition and sampling}

$P$. infestans strains were routinely grown at $18^{\circ} \mathrm{C}$ in the dark on $\mathrm{V} 8$ media or on Rye agar medium supplemented with $2 \%$ sucrose [7]. Extracellular medium was obtained by flooding full grown plates with V8 medium. After overnight incubation samples were taken and immediately centrifuged for $2 \mathrm{~min}$ at 10,000 g. The supernatant was collected and filtered over $0.2 \mu \mathrm{M}$ filters to remove cell debris.

\section{Plant cell suspension culturing and radio-labelling of phospholipids}

Cell suspensions of Nicotiana tabacum were grown as described [8]. Metabolically labelled ${ }^{32}$ P-labelled phospholipids were obtained by overnight incubation of $1-2 \mathrm{ml}$ cell suspension with

Table 1. PLDs in Phytophthora infestans.

\begin{tabular}{|c|c|c|c|c|c|c|c|c|c|c|c|}
\hline Class & $\begin{array}{l}\text { Proposed } \\
\text { name }\end{array}$ & $\begin{array}{l}\text { Gene } \\
\text { number }\end{array}$ & Scaffold & $\begin{array}{l}\text { Protein } \\
\text { accession }\end{array}$ & Intron & $\begin{array}{l}\text { Protein } \\
\text { length }\end{array}$ & $\begin{array}{l}\text { Signal } \\
\text { peptide } \\
\text { prediction }\end{array}$ & $\begin{array}{l}\text { ESTs } \\
\text { Nr. }\end{array}$ & $\begin{array}{l}\text { P. sojae } \\
\text { homolog } \\
\text { (BlastP) }\end{array}$ & $\begin{array}{l}\text { P. ramorum } \\
\text { homolog } \\
\text { (BlastP) }\end{array}$ & $\begin{array}{l}\text { Highest homology, BlastP hit } \\
\text { (acc. nr., organism, E-value); } \\
\text { Sequences outside } P \text {. infestans } \\
\text { strain T30-4 }\end{array}$ \\
\hline $\begin{array}{l}\text { PXPH- } \\
\text { PLD }\end{array}$ & PXPH-PLD & $\begin{array}{l}\text { PITG_ } \\
03651\end{array}$ & 4 & EEY66109 & 1 & 1119 & - & 5 & $\begin{array}{l}\text { PLD_- } \\
134882\end{array}$ & PLD_84787 & CBI22957; Vitis vinifera; 2e-141 \\
\hline $\begin{array}{l}\text { PXTM- } \\
\text { PLD }\end{array}$ & PXTM-PLD & $\begin{array}{l}\mathrm{PITG}_{-} \\
00284\end{array}$ & 1 & EEY57717 & 0 & 1807 & - & 3 & $\begin{array}{l}\text { PLD_- } \\
163010\end{array}$ & PLD_101442 & $\begin{array}{l}\text { Q5BMR2; } \\
\text { Phytophthora infestans; } 0.0\end{array}$ \\
\hline $\begin{array}{l}\text { TM- } \\
\text { PLD }\end{array}$ & TM-PLD & $\begin{array}{l}\mathrm{PITG}_{-} \\
16798\end{array}$ & 49 & EEY65487 & 0 & 874 & - & 2 & $\begin{array}{l}\text { PLD_ } \\
128805\end{array}$ & PLD_81941 & $\begin{array}{l}\text { XP_002452125; } \\
\text { Sorghum bicolor; 1e-12 }\end{array}$ \\
\hline $\begin{array}{l}\text { sPLD- } \\
\text { like-A }\end{array}$ & sPLD-like-1 & $\begin{array}{l}\mathrm{PITG}_{-} \\
18185\end{array}$ & 63 & EEY67671 & 0 & 549 & 0.484 & 2 & $\begin{array}{l}\text { PLD_- } \\
139486\end{array}$ & PLD_81884 & $\begin{array}{l}\text { XP_002515425; } \\
\text { Ricinus communis; 5e-55 }\end{array}$ \\
\hline $\begin{array}{l}\text { sPLD- } \\
\text { like-B }\end{array}$ & sPLD-like-2 & $\begin{array}{l}\mathrm{PITG}_{-} \\
00616\end{array}$ & 1 & EEY58009 & 0 & 558 & 0.998 & 0 & $\begin{array}{l}\text { PLD_- } \\
140963\end{array}$ & PLD_79972 & $\begin{array}{l}\text { YP_003339462; } \\
\text { Streptosporangium roseum; 1e-33 }\end{array}$ \\
\hline $\begin{array}{l}\text { sPLD- } \\
\text { like-B }\end{array}$ & sPLD-like-3 & $\begin{array}{l}\text { PITG_ }_{2} \\
20602\end{array}$ & 181 & EEY56690 & 0 & 558 & 0.997 & 0 & $\begin{array}{l}\text { PLD }_{-} \\
140963\end{array}$ & PLD_79972 & $\begin{array}{l}\text { YP_003339462; Streptosporangium } \\
\text { roseum; 4e-31 }\end{array}$ \\
\hline $\begin{array}{l}\text { SPLD- } \\
\text { like-B }\end{array}$ & sPLD-like-4* & $\begin{array}{l}\text { PITG_ } \\
20603\end{array}$ & 181 & EEY56691 & 0 & 562 & 1 & 0 & $\begin{array}{l}\text { PLD }_{-} \\
140963\end{array}$ & PLD_79972 & $\begin{array}{l}\text { YP_003383471; } \\
\text { Kribbella flavida; } 6 e-36\end{array}$ \\
\hline $\begin{array}{l}\text { sPLD- } \\
\text { like-B }\end{array}$ & sPLD-like-5 & $\begin{array}{l}\mathrm{PITG}_{-} \\
00617\end{array}$ & 1 & EEY58010 & 0 & 562 & 1 & 0 & $\begin{array}{l}\text { PLD }_{-} \\
140963\end{array}$ & PLD_72867 & $\begin{array}{l}\text { YP_003383471; } \\
\text { Kribbella flavida; } 2 e-36\end{array}$ \\
\hline $\begin{array}{l}\text { sPLD- } \\
\text { like-B }\end{array}$ & sPLD-like-6 & $\begin{array}{l}\mathrm{PITG}_{-} \\
22809\end{array}$ & 10 & EEY53326 & 0 & 568 & 1 & 0 & $\begin{array}{l}\text { PLD }_{-} \\
163070\end{array}$ & PLD_101467 & $\begin{array}{l}\text { YP_003383471; } \\
\text { Kribbella flavida; } 9 e-38\end{array}$ \\
\hline $\begin{array}{l}\text { sPLD- } \\
\text { like-B }\end{array}$ & sPLD-like-7 & $\begin{array}{l}\text { PITG_ } \\
06994\end{array}$ & 10 & EEY53348 & 0 & 571 & 0.991 & 0 & $\begin{array}{l}\text { PLD_- } \\
138732\end{array}$ & PLD_101476 & $\begin{array}{l}\text { YP_001106428; Saccharopolyspora } \\
\text { erythraea; 2e-36 }\end{array}$ \\
\hline $\begin{array}{l}\text { sPLD- } \\
\text { like-B }\end{array}$ & sPLD-like-8 & $\begin{array}{l}\text { PITG_ } \\
10568\end{array}$ & 18 & EEY57013 & 0 & 578 & 0.997 & 0 & $\begin{array}{l}\text { PLD_- } \\
138544\end{array}$ & PLD_84378 & $\begin{array}{l}\text { YP_003339462; } \\
\text { Streptosporangium roseum; 1e-38 }\end{array}$ \\
\hline $\begin{array}{l}\text { sPLD- } \\
\text { like-B }\end{array}$ & sPLD-like-9 & $\begin{array}{l}\text { PITG_ } \\
10572\end{array}$ & 18 & EEY57017 & 0 & 589 & 1 & 0 & $\begin{array}{l}\text { PLD_- } \\
138537\end{array}$ & PLD_72867 & $\begin{array}{l}\text { YP_884788; Mycobacterium } \\
\text { smegmatis; 2e-40 }\end{array}$ \\
\hline $\begin{array}{l}\text { sPLD- } \\
\text { like-B }\end{array}$ & sPLD-like-10 & $\begin{array}{l}\text { PITG_ } \\
10563\end{array}$ & 18 & EEY57009 & 0 & 598 & 0.999 & 0 & $\begin{array}{l}\text { PLD_- } \\
138537\end{array}$ & PLD_101476 & $\begin{array}{l}\text { YP_884788; Mycobacterium } \\
\text { smegmatis; 2e-37 }\end{array}$ \\
\hline $\begin{array}{l}\text { sPLD- } \\
\text { like-B }\end{array}$ & sPLD-like-11* & $\begin{array}{l}\mathrm{PITG}_{-} \\
12809\end{array}$ & 27 & EEY60394 & 0 & 598 & 0.992 & 0 & $\begin{array}{l}\text { PLD_- } \\
138732\end{array}$ & PLD_72867 & $\begin{array}{l}\text { YP_884788; Mycobacterium } \\
\text { smegmatis; 8e-36 }\end{array}$ \\
\hline $\begin{array}{l}\text { sPLD- } \\
\text { like-B }\end{array}$ & sPLD-like-12 & $\begin{array}{l}\mathrm{PITG}_{-} \\
12806\end{array}$ & 27 & EEY60392 & 0 & 605 & 0.989 & 1 & $\begin{array}{l}\text { PLD_ } \\
138537\end{array}$ & PLD_101476 & $\begin{array}{l}\text { YP_884788; Mycobacterium } \\
\text { smegmatis; 4e-39 }\end{array}$ \\
\hline $\begin{array}{l}\text { PLD- } \\
\text { like }\end{array}$ & PLD-like-1 & $\begin{array}{l}\mathrm{PITG}_{-} \\
00921\end{array}$ & 1 & EEY58277 & 0 & 531 & - & 48 & $\begin{array}{l}\text { PLD_ } \\
127024\end{array}$ & PLD_77742 & $\begin{array}{l}\text { YP_003339462; } \\
\text { Streptosporangium roseum; 2e-38 }\end{array}$ \\
\hline $\begin{array}{l}\text { PLD- } \\
\text { like }\end{array}$ & PLD-like-2 & $\begin{array}{l}\text { PITG }_{2} \\
21129\end{array}$ & 228 & EEY59066 & 0 & 542 & - & 0 & $\begin{array}{l}\text { PLD_ } \\
138537\end{array}$ & PLD_72867 & $\begin{array}{l}\text { YP_884788; Mycobacterium } \\
\text { smegmatis; 1e-40 }\end{array}$ \\
\hline $\begin{array}{l}\text { PLD- } \\
\text { like }\end{array}$ & PLD-like-3 & $\begin{array}{l}\mathrm{PITG}_{-} \\
00923\end{array}$ & 1 & EEY58278 & 0 & 556 & - & 0 & $\begin{array}{l}\text { PLD_ } \\
127026\end{array}$ & PLD_77744 & $\begin{array}{l}\text { YP_003383471; } \\
\text { Kribbella flavida; 2e-37 }\end{array}$ \\
\hline
\end{tabular}

*Pseudogenes; for the phylogram shown in Figure 2, the ORFs were 'restored' by introducing a ' $T$ ' at position 180741 in supercontig 1.181 for sPLD-like-4 and 'GA' at position 1472900 in supercontig 1.27

doi:10.1371/journal.pone.0017767.t001 
Table 2. Conserved motifs detected in P. infestans PLDs.

\begin{tabular}{|c|c|c|c|c|c|c|c|}
\hline \multirow[b]{2}{*}{ Name } & \multirow[b]{2}{*}{ Gene number } & \multirow[b]{2}{*}{ HKD1 } & \multirow[b]{2}{*}{ HKD2 } & \multicolumn{4}{|c|}{ Conserved regulatory domains/motifs } \\
\hline & & & & PIP $_{2}$-binding & "IYIENQFF" & “DRY/RVYVVV" & "IGSANIN" \\
\hline PXPH-PLD & PITG_03651 & HKD & HKD & + & HFVYIENQFF & $+(\mathrm{EKF}) /+$ & IGSANIN \\
\hline PXTM-PLD & PITG_00284 & HKD & HKD & + & HFLYIENQFF & $+(\mathrm{EKF}) /+$ & LGSANIN \\
\hline TM-PLD & PITG_16798 & HKD & HKN & - & - & $+(\mathrm{EPF}) /-$ & - \\
\hline sPLD-like-1 & PITG_18185 & HKD & HKD & - & - & $-1-$ & VGSANMD* \\
\hline sPLD-like-2 & PITG_00616 & HKL & HKD & + & NFIFIEDQYF & $-/+$ & VGSANWN \\
\hline sPLD-like-3 & PITG_20602 & $\mathrm{HKL}$ & HKD & + & NFIFIEDQYF & $-1+$ & VGSANWN \\
\hline sPLD-like-5 & PITG_00617 & HKT & HKD & + & NFIYIEDQYF & $-/+$ & VGSANWN \\
\hline sPLD-like-6 & PITG_22809 & HKT & HKD & + & NFIYVEDQYF & $-1+$ & IGSANWN \\
\hline sPLD-like-7 & PITG_06994 & HKA & HKD & + & NYIYIEDQYF & $-/+$ & VGSSNWN \\
\hline sPLD-like-8 & PITG_10568 & HKA & HKD & + & NFVYIEDQYF & $-/+$ & DGSANWN \\
\hline sPLD-like-9 & PITG_10572 & HKA & HKD & + & NFIYIEDQYF & $-/+$ & VGSANWN \\
\hline sPLD-like-10 & PITG_10563 & HKA & HKD & + & NFIYIEDQYF & $-1+$ & LGSANWN \\
\hline sPLD-like-12 & PITG_12806 & HKA & HKD & + & NFICIEDQYF & $-/+$ & VGSANWN \\
\hline PLD-like-1 & PITG_00921 & HKR & HKD & + & NYIFIQDQYF & $-/+$ & LGSANWN \\
\hline PLD-like-2 & PITG_21129 & HKA & HKD & + & NFIYIEDQYF & $-/+$ & VGSANWN \\
\hline PLD-like-3 & PITG_00923 & HKR & HKD & + & NYIFIQDQYF & $-/+$ & LGSANWN \\
\hline PXPH-PLD & PITG_03651 & HKD & HKD & + & HFVYIENQFF & $+(\mathrm{EKF}) /+$ & IGSANIN \\
\hline
\end{tabular}

$\mathrm{PIP}_{2}$ binding domain and DRY/RVYVVV motifs are indicated as present $(+)$, or absent $(-)$. For other motifs the amino acid sequences are shown. *This "IGSANIN" motif is found directly downstream of HKD1 (see text).

doi:10.1371/journal.pone.0017767.t002

$100 \mu \mathrm{Ci}$ carrier-free ${ }^{32} \mathrm{PO}_{4}{ }^{3-}$ (GE Healthcare, Diegem, Belgium). The labelled cells were divided into $200 \mu$ aliquots in 2-ml Eppendorf vials and labelling was terminated by the addition of $20 \mu \mathrm{l}$ perchloric acid $(50 \%, \mathrm{v} / \mathrm{v})$. After brief vortexing, the samples were frozen in liquid nitrogen. After $5 \mathrm{~min}, 450 \mu \mathrm{l}$ $\mathrm{CHCl}_{3}: \mathrm{MeOH}: \mathrm{HCl}(50: 100: 1, \mathrm{v} / \mathrm{v})$ was added and the mixture was briefly mixed and snap-frozen in liquid nitrogen. During thawing the tubes were shaken vigorously and thereafter snapfrozen again to improve lipid recovery. After subsequent thawing, $450 \mu \mathrm{CHCl}_{3}$ and $200 \mu \mathrm{l} 0.9 \%$ (w/v) NaCl was added to induce a two-phase system. Tubes were then vigorously shaken for 15$30 \mathrm{~min}$ and centrifuged for $2 \mathrm{~min}$. The lower-phase was transferred to a fresh tube containing $450 \mu \mathrm{CHCl}_{3}: \mathrm{MeOH}: 1 \mathrm{M}$ $\mathrm{HCl}(3: 48: 47, \mathrm{v} / \mathrm{v})$, mixed for $1 \mathrm{~min}$ and centrifuged for $2 \mathrm{~min}$. Subsequently the upper-phase was removed and the lower organic phase was dried under a stream of $\mathrm{N}_{2}(\mathrm{~g})$ and the isolated lipids were dissolved in $20 \mu \mathrm{CHCl}_{3}$ and stored at $-20^{\circ} \mathrm{C}$ until usage.

\section{Phospholipase D assay}

The metabolically labelled phospholipids were dried under $\mathrm{N}_{2}$ (g) and resuspended into vesicles in $200 \mu \mathrm{l} 10 \mathrm{mM}$ Tris buffer (pH 6.4) by sonication (VWR ultrasonic cleaner). Aliquots (10 $\mu \mathrm{l})$ were supplemented with $5 \mu \mathrm{l}$ buffer containing $40 \%$ propanol. The assay was initiated by adding $85 \mu \mathrm{l}$ medium (control) or medium in which $P$. infestans was cultured (extracellular medium), followed by a 1 hour incubation at room-temperature. The reaction was stopped by adding $375 \mu \mathrm{l} \quad \mathrm{CHCl}_{3}: \mathrm{MeOH}: \mathrm{HCl}$ $(50: 100: 1[\mathrm{v} / \mathrm{v}])$, and processed as described [8].

\section{TLC analysis}

Lipid samples were separated by thin layer chromatography on Merck silica 60 TLC plates (Darmstadt, Germany) using the ethyl acetate system as described [9]. Radiolabelled phospholipids were visualized by phosphoimaging (Storm, Molecular Dynamics; Sunnyvale, GA, USA).

\section{Results}

Sixteen genes in $P$. infestans encode proteins with phospholipase D hallmarks

The genome sequence of $P$. infestans harbours eighteen genes encoding a PLD, all of which can be classified in the subfamilies identified previously in $P$. sojae and $P$. ramorum (Table 1). PXPHPLD, PXTM-PLD and TM-PLD are single copy genes. Three genes encode members of the PLD-like subfamily and the remaining twelve encode putatively secreted PLDs (sPLD-likes) based on the presence of a predicted SP. Alignments revealed that eleven sPLD-likes share sustained protein similarity $(>50 \%$ overall identity) whereas one (sPLD-like-1) lacks significant identity with any of the others $(15 \%$; Table S1). sPLD-like-1 was therefore designated as a type A (sPLD-like-A) and the others as type B (sPLD-like-B). Two of the latter, sPLD-like-4 and -11, lack continuous open reading frames (ORFs) and are considered as pseudogenes. In retrospect, also $P$. sojae and $P$. ramorum have one sPLD-like-A ortholog (Table 1).

The PLD proteins were analyzed for characteristic conserved motifs (Table 2). The two catalytic motifs HKD1 and HKD2 are conserved in $P$. infestans PXTM-PLD, PXPH-PLD and sPLD-likeA. In TM-PLD, the PLD-likes and SPLD-like-Bs one HKD motif is modified. In TM-PLD HKD2 is changed in HND, as in the $P$. sojae and $P$. ramorum TM-PLDs. The PLD-likes and sPLD-likes lack the aspartate residue (D) of HKD1 at the expected position.

Additional motifs in PLDs have been recognized as regulatory or binding domains. In PXPH-PLD both the PX and PH domain are readily conserved. PXTM-PLD contains a PX domain and five transmembrane domains [6]. A remnant of a $\mathrm{PH}$ domain $\left(\mathrm{E}-\right.$ value $\left.1.64 \mathrm{E}^{+03}\right)$ was detected between transmembrane domains 


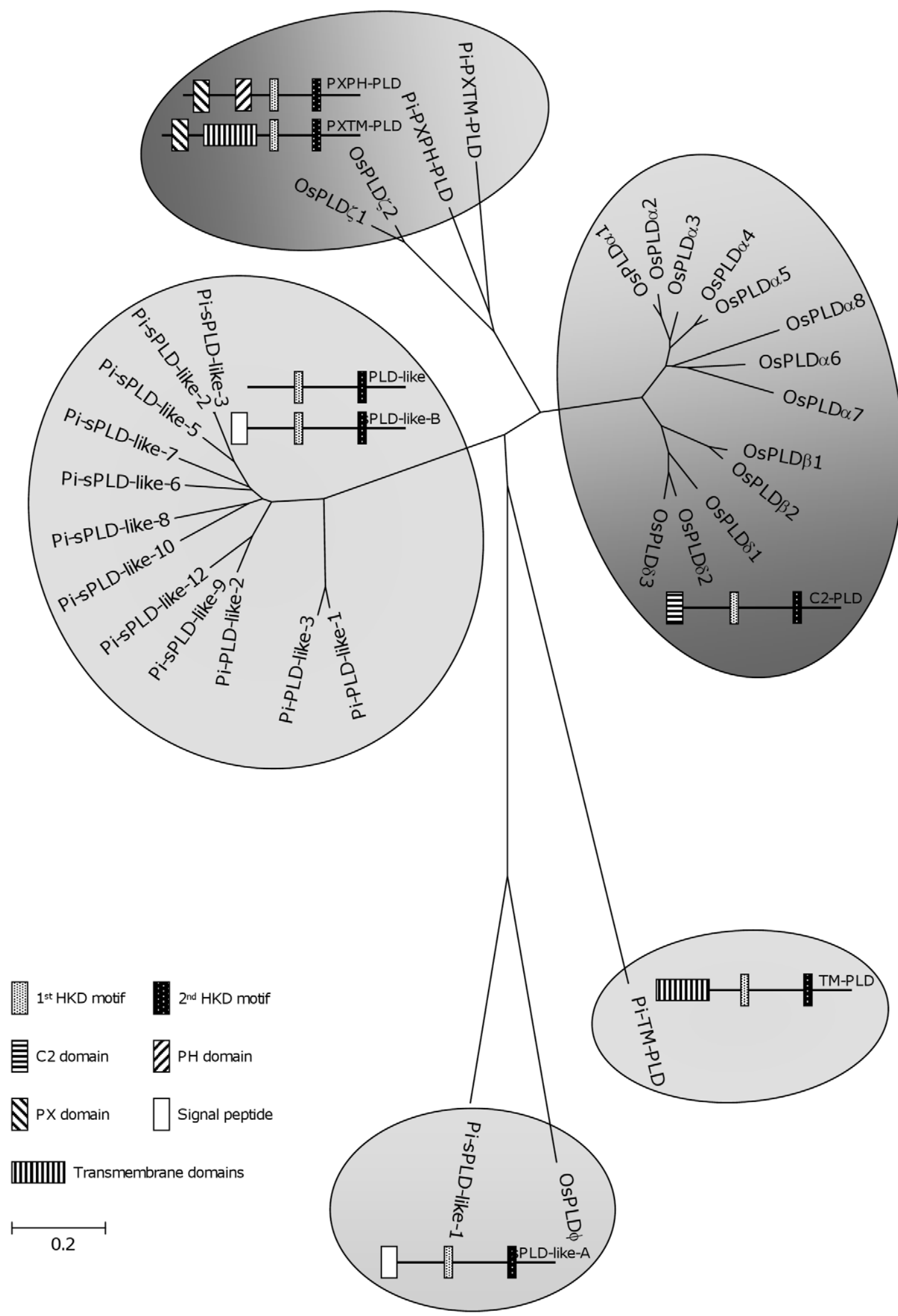

Figure 1. Phylogram of PLDs in $P$. infestans and rice (Oryza sativa). A consensus minimal evolution tree was constructed based on the AA sequences comprising the catalytic motifs and intermediate regions of PLDs in $P$. infestans and O. sativa. OsPLDK was excluded from the analysis because it lacks the catalytic motifs. For accession numbers of the $P$. infestans sequences see Table 1. For rice sequences see Li et al. [3]. doi:10.1371/journal.pone.0017767.g001 


\section{P. infestans P. sojae P. ramorum}
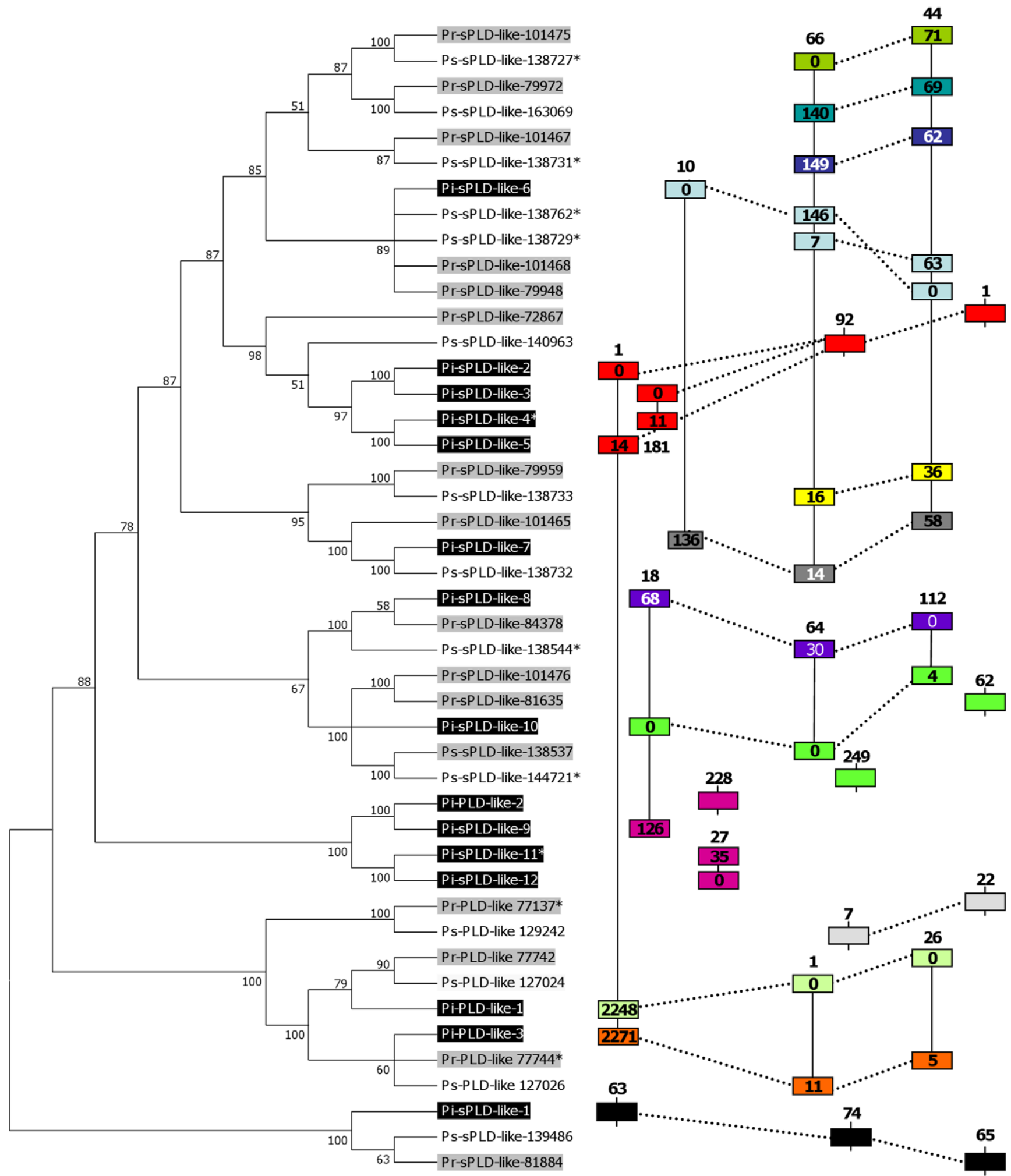

Figure 2. Phylogram and genome organization of Phytophthora PLD-likes and sPLD-likes. The phylogram shown on the left was constructed based on AA sequences. (s)PLD likes from $P$. infestans and $P$. ramorum are shown in black and gray respectively. Pseudogenes (marked by *; see Table 1 and [4]) were included in the analysis. On the right, the vertical lines represent scaffolds containing one or more (s)PLD-like genes (rectangles). The scaffold numbers are shown above or below each line. On scaffolds with two or more (s)PLD-like genes the number in each rectangle indicates the distance in kb between the start of this gene and the start of the first PLD-like gene (marked by 0) on the scaffold. (s)PLD-likes that cluster in the phylogram have the same color. Dotted lines connecting the scaffolds indicate that the genomic regions are syntenic. doi:10.1371/journal.pone.0017767.g002 
two and three. As described previously PXTM-PLD has a "PIP $2_{2}$ binding domain", a "PC-binding site" (IYIENQFF motif) and a G $\alpha$-protein binding motif DRY/RVYVVV between HKDl and HKD2 [6]. In human HsPLD2 and Arabidopsis AtPLD 8 , the $\mathrm{PIP}_{2^{-}}$ binding domain was recently identified as a tubulin binding region and the IYIENQFF and the DRY/VYVVV motifs appear to act as an actin binding fragment $[10,11,12]$. P. infestans PXPH-PLD and PXTM-PLD encompass all these domains. Both, the $\mathrm{PIP}_{2}$-binding domain and the IYIENQFF motif are present in PLD-likes and sPLD-like-Bs. Notably, in these cases the C-terminal hydrophobic region of the DRY/RVYVVV motif is conserved but the DRY motif is not found. In PXTM-PLD and plant PLDs it is replaced by EKF [6]. In TM-PLD an EPF is located at the expected position but the hydrophobic region is lacking. sPLD-like-1 solely consists of the catalytic site with the two HKD motifs (Table 2).

Downstream of HKD2, PXPH-PLDs and C2-PLDs contain a so-called IGSANIN motif that is supposed to play a role in membrane attachment. The motif is fully conserved in PXPHPLD whereas in PXTM-PLD, the PLD-likes and sPLD-like-Bs a slightly modified motif is found. In TM-PLD the motif is barely

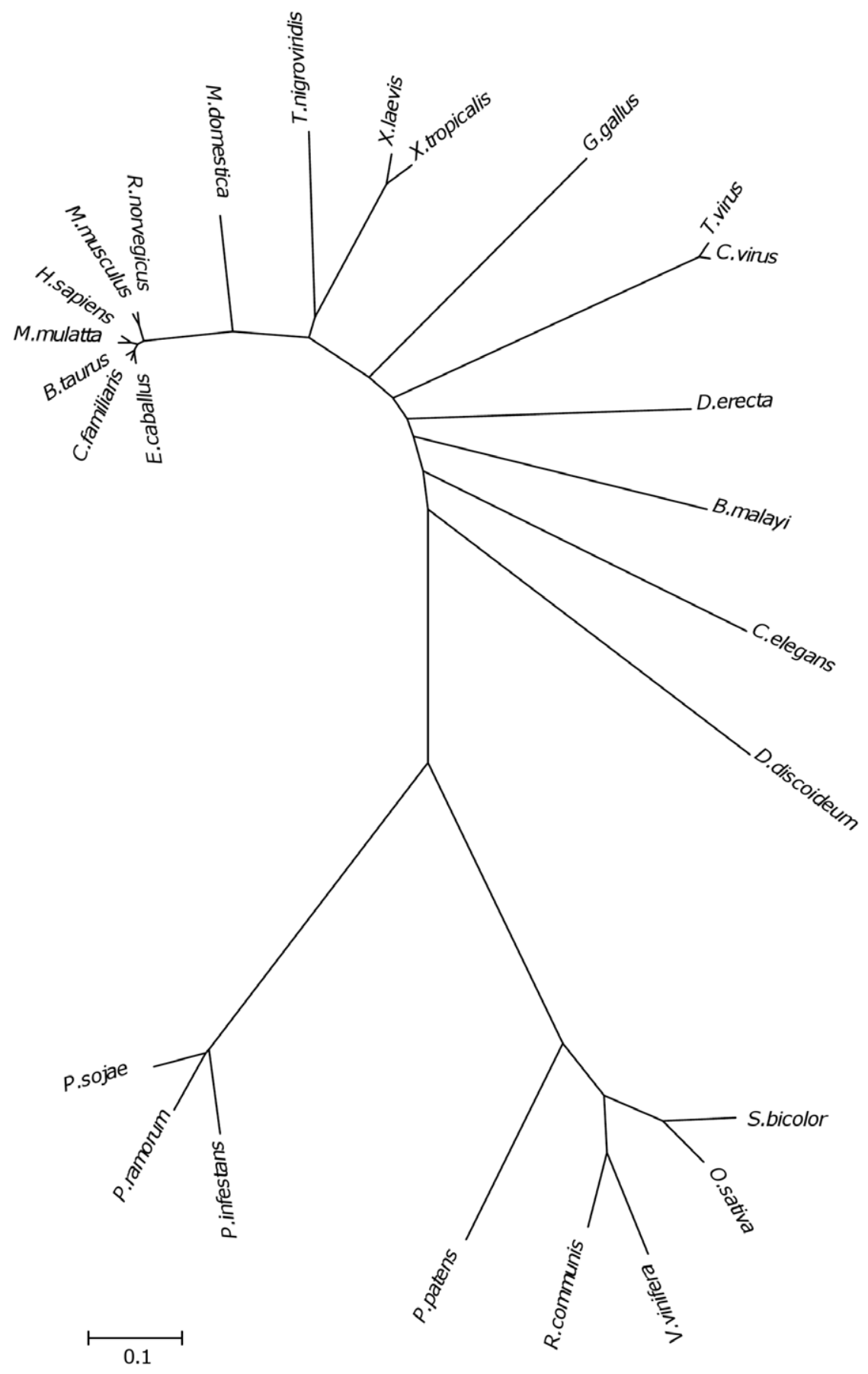

Figure 3. Phylogram of Phytophthora sPLD-like-A orthologs and their homologs in various organisms. The consensus minimal evolution tree constructed from the amino acid sequences is shown. For protein sequence identifiers see Table 3 .

doi:10.1371/journal.pone.0017767.g003 
recognizable; only two out of seven amino acids are conserved. sPLD-like-A lacks the motif but instead has a "VGSANMD" motif that is located directly downstream of HKD1 (Table 2).

\section{Phylogenetic relationships of PLD genes}

To analyse the relationship between Phytophthora PLDs and those of other organisms, PLD sequences were retrieved from genome databases. For an overall comparison, $P$. infestans PLDs were clustered with the 16 PLDs encoded in the rice genome. Rice has a putatively secreted PLD (OsPLD $\varphi)$ and hence, has three PLD subfamilies [3].P. infestans PXPH-PLD and PXTM-PLD cluster with rice PXPH-PLDs. Most sPLD-likes and PLD-likes cluster in one large clade separated from the rice C2-PLDs. The sPLD-like-A of $P$. infestans clusters with OsPLD $\phi$. TM-PLD is an outlier that is absent in rice (Figure 1).

Further study revealed that PXPH-PLDs from plants and mammals are the closest homologs of $P$. infestans PXTM-PLD and PXPH-PLD (not shown). For TM-PLD, low similarity was found only with three $P$. infestans proteins with a DUF803 domain (PITG_05621, PITG_09535 and PITG_12469). Since the DUF803 domain corresponds to the transmembrane domains an additional analysis was performed for the C-terminal part harbouring the catalytic site. With an E-value of $6 \mathrm{e}^{-6}$ a PLD from Phaeobacter gallaeciensis (ZP_02144336) was the closest homolog.

\section{Evolution of (s)PLD-like genes in Phytophthora}

The large number of PLD-like and sPLD-likes genes in Phytophthora could point to gene duplication events in a common ancestor. To investigate this we constructed a phylogram of all (s)PLD-likes in the three Phytophthora species (Figure 2). The PLDlikes with the exception of Pi-PLD-like-2 group in one clade and Pi-PLD-like- 1 and -3 each have their own ortholog in P. sojae and $P$. ramorum. The bulk of the tree represents the sPLD-like-B family and remarkably includes Pi-PLD-like-2 that groups with three PisPLD-like-B genes, i.e. Pi-sPLD-like-9, -11 and -12 , in a distinct $P$. infestans specific subclade. Another $P$. infestans specific cluster is observed in the subclade comprising Pi-sPLD-like-2, -3, -4 and -5 which all four group with the same ortholog in $P$. sojae and $P$. ramorum. Other subclades lack a $P$. infestans ortholog. This nonuniform distribution is also evident in Table 1 in which the closest homologs of the $P$. infestans (s)PLD-like genes are listed based on BlastP. Several sPLD-like-Bs share the same $P$. sojae or $P$. ramorum protein as closest homolog rather than having unique sets of three orthologs representing one copy in each of the species. This suggests that some sPLD-like-Bs in P. infestans evolved directionally so that the paralogs are more related to each other than to orthologs. Despite this close relationship the paralogs still show significant differences at identity level (Table S1).

Table 3. Characteristics of sPLD-like-A homologs.

\begin{tabular}{|c|c|c|c|c|c|c|c|c|c|}
\hline \multirow[b]{2}{*}{ Organism } & \multirow[b]{2}{*}{ NCBI Nr. } & \multirow[b]{2}{*}{ BlastP } & \multirow[b]{2}{*}{ Protein } & \multicolumn{2}{|c|}{ N-terminus } & \multirow{2}{*}{$\frac{\text { Cleavage }}{\text { position }}$} & \multirow[b]{2}{*}{ HKD1 } & \multirow[b]{2}{*}{ HKD2 } & \multirow[b]{2}{*}{ VGSANMD } \\
\hline & & & & SP & SA & & & & \\
\hline P. infestans & EEY67671 & - & 549 & 0.48 & 0.52 & $28 / 29$ & HKD & HKD & VGSANMD \\
\hline P. sojae & - & 0.0 & 560 & 0.68 & 0.32 & $43 / 44$ & HKD & HKD & VGSANMD \\
\hline P. ramorum & - & 0.0 & 550 & 0.17 & 0.83 & $31 / 32$ & HKD & HKD & VGSANMD \\
\hline Ricinus communis & XP_002515425 & $5 \mathrm{E}-55$ & 516 & 0.93 & 0.07 & $28 / 29$ & HKD & HKD & IGSANND \\
\hline Oryza sativa & NP_001058220 & $2 \mathrm{E}-53$ & 512 & 1 & 0 & $28 / 29$ & HKD & HKD & IGSANND \\
\hline Physcomitrella patens & XP_001769226 & $2 \mathrm{E}-52$ & 511 & 1 & 0 & $17 / 18$ & HKN & HKD & LGSANND \\
\hline Sorghum bicolor & XP_002438759 & $8 \mathrm{E}-52$ & 516 & 1 & 0 & $28 / 29$ & HKD & HKD & IGSANND \\
\hline Vitis vinifera & XP_002285518 & $4 \mathrm{E}-54$ & 514 & 0.98 & 0.02 & $24 / 25$ & HKD & HKD & IGSANND \\
\hline Dictyostelium discoideum & XP_637114 & $2 \mathrm{E}-42$ & 438 & 0.96 & 0 & $19 / 20$ & HKD & HKE & VGSANAD \\
\hline Drosophila erecta & XP_001974062 & $1 \mathrm{E}-44$ & 493 & 0 & 0 & - & HKD & HKD & LGSANMD \\
\hline Caenorhabditis elegans & NP_504824 & $1 \mathrm{E}-40$ & 516 & 0 & 0 & - & HKD & HKD & IGSANMD \\
\hline Brugia malayi & XP_001902241 & $3 \mathrm{E}-51$ & 432 & 0 & 0 & - & HKD & HKD & LGSANLD \\
\hline Taterapox virus & YP_717345 & $6 \mathrm{E}-38$ & 424 & 0 & 0 & - & HKD & HKD & LGSANMD \\
\hline Cowpox virus & ABD97389 & $1 \mathrm{E}-38$ & 424 & 0 & 0 & - & HKD & HKD & LGSANMD \\
\hline Xenopus laevis & NP_001083260 & $2 \mathrm{E}-40$ & 493 & 0 & 1 & $52 / 53$ & HKD & HKD & IGSANMD \\
\hline Xenopus tropicalis & NP_001011023 & $4 \mathrm{E}-39$ & 494 & 0 & 1 & $52 / 53$ & HKD & HKD & IGSANMD \\
\hline Tetraodon nigroviridis & CAG12726 & $6 \mathrm{E}-34$ & 493 & 0 & 0.99 & $49 / 50$ & HKD & HKD & IGSANMD \\
\hline Gallus gallus & XP_421399 & $1 \mathrm{E}-33$ & 517 & 0.01 & 0.51 & $43 / 44$ & HKD & HKD & IGSANMD \\
\hline Monodelphis domesticus* & XP_001371155 & $2 \mathrm{E}-44$ & 486 & 0 & 0.98 & $47 / 48$ & HKD & HKD & IGSANMD \\
\hline Mus musculus & O35405 & $1 \mathrm{E}-43$ & 488 & 0 & 1 & $51 / 52$ & HKD & HKE & LGSANMD \\
\hline Rattus norvegicus & NP_001012167 & $4 \mathrm{E}-43$ & 488 & 0 & 1 & $51 / 52$ & HKD & HKE & LGSANMD \\
\hline Macaca mulatta & XP_001093926 & $2 \mathrm{E}-43$ & 492 & 0 & 1 & $51 / 52$ & HKD & HKE & LGSANMD \\
\hline Homo sapiens & NP_001026866 & $5 \mathrm{E}-42$ & 490 & 0 & 1 & $51 / 52$ & HKD & HKE & LGSANMD \\
\hline Bos Taurus & Q2KJJ8 & $4 \mathrm{E}-44$ & 490 & 0 & 1 & $51 / 52$ & HKD & HKE & LGSANMD \\
\hline Equus caballus & XP_001498901 & $1 \mathrm{E}-43$ & 490 & 0 & 1 & $51 / 52$ & HKD & HKE & LGSANMD \\
\hline Canis familiaris & XP_853110 & $2 E-42$ & 490 & 0 & 1 & $51 / 52$ & HKD & HKE & IGSANMD \\
\hline
\end{tabular}

*Based on alignments, Met84 was taken as protein start.

doi:10.1371/journal.pone.0017767.t003 


\section{$P$. infestans PLD genes are dispersed in the genome}

The PLD genes in $P$. infestans are dispersed over nine scaffolds (Table 1; Figure 2). Five genes are located on scaffold_1, including two sPLD-like-B genes that are $12 \mathrm{~kb}$ apart, and two PLD-like genes, $21 \mathrm{~kb}$ apart. Three sPLD-like-B genes are located on scaffold_18 spanning $127 \mathrm{~kb}$. Also the two sPLD-like-B genes on scaffold_10 are far apart (135 kb). Scaffold_27 and scaffold_181 have two sPLD-like-B genes whereas sPLD-like-A is located on scaffold_63. When compared to P. sojae and P. ramorum, the distribution of PLD genes within $P$. infestans seems more dispersed. For example, in $P$. sojae, six sPLD-like-B genes are located within an $18 \mathrm{~kb}$ region and similarly, in P. ramorum, five within $15 \mathrm{~kb}$ [4].
To examine the extent of synteny between species, genomic regions flanking each PLD gene were analysed. The average intergenic length was $1.7 \mathrm{~kb}, 2.4 \mathrm{~kb}$ and $6.7 \mathrm{~kb}$, respectively, for $P$. ramorum, $P$. sojae and $P$. infestans. The regions carrying sPLD-like1 (Figure 2) and the single copy genes PXPH-PLD, PXTM-PLD and TM-PLD (not shown) showed conserved synteny. The majority of the PLD-like and sPLD-like genes in P. infestans are surrounded by genes that co-localize with PLD-like and sPLD-like genes in the other two species although genes are often rearranged (Figure 2). Scaffold_181 of $P$. infestans might have been the result of a duplication event involving Scaffold_1. For both PLD-like-2 and sPLD-like-9, some of the surrounding genes were found on $P$. sojae

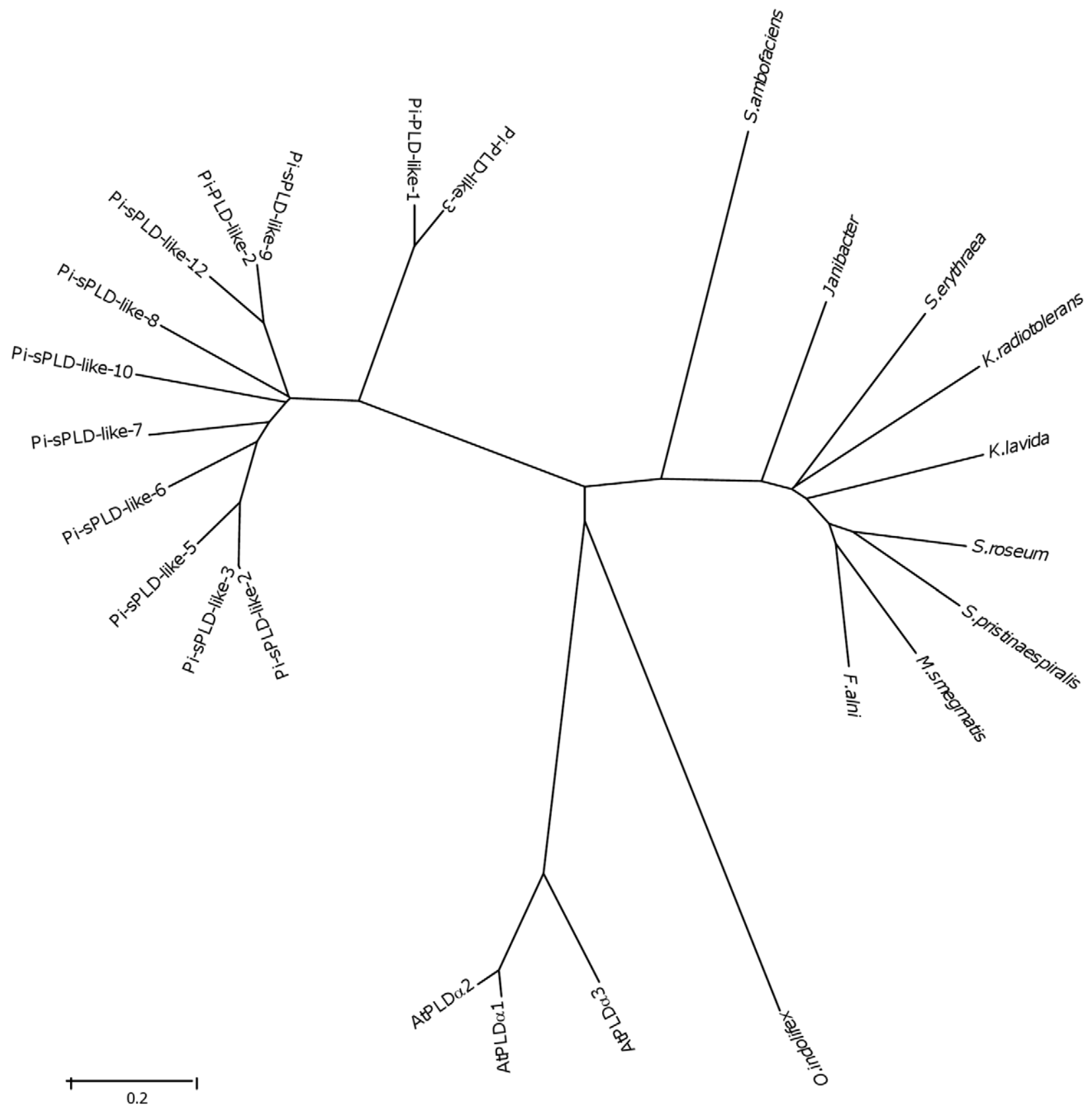

Figure 4. Alignment of amino acid sequences of type A sPLD-likes. Sequences are from Phytophthora ( $P$. infestans sPLD-like-1), Grape (XP_002285518), Human (NP_001026866), Drosophila (XP_001974062) and Taterapox (YP_717345). The symbols used are [*] for identical, [;] for conservative and [.] for semi-conservative amino acid residues. Signal peptides/signal anchors are in italics, HKD motifs in bold and the "IGSANIN" motif is underlined.

doi:10.1371/journal.pone.0017767.g004 
Phytophthora Human

Drosophila

Grape

Taterapox

Phytophthora

Human

Drosophila

Grape

Taterapox

Phytophthora

Human

Drosophila

Grape

Taterapox

Phytophthora

Human

Drosophila

Grape

Taterapox

Phytophthora

Human

Drosophila

Grape

Taterapox

Phytophthora

Human

Drosophila

Grape

Taterapox

Phytophthora

Human

Drosophila

Grape

Taterapox

Phytophthora

Human

Drosophila

Grape

Taterapox

Phytophthora Human

Drosophila

Grape

Taterapox

Phytophthora Human

Drosophila

Grape

Taterapox

Phytophthora

Human

Drosophila

Grape

Taterapox
MPRRLSRGDGAALFGLLWAASCVFLVALRFTPREIANSATPA 42 --MKPKLMYQE L KVPAEEPANE L PMNE IEAWKAAEKKARWVLLVL ILAVVGFGALMTQLF 58 MPEYKKLEDQEPDVENAT STVONTAPVQVAGEGQRTAASQQAGQMVTVSLFMLLELGSSY 60 ---

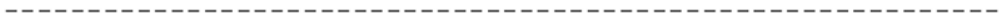

SKSRVFDPKWTSDSVSNELLTGKATLSLVESLPVGDFDLSSSVP--QTFEALTRHVVAAK 100 LWEYGDLHLF-GPNORPAPCYDPCEAVLVES I PEGLDFPNASTGNPST SOAWLGLLAGAH 117 FQPRPRLHQYKGGRGHGLQEKEACN IQLVES I P IGLTYPDGSPRELSTYEAWLKLLESAK 120 -----KSSSQCKAWIVQS IPTHMPHLPPVSGVLSTADVFQWLAGNSS 66 -------------MNMDNT I AVITET I P I GMQFD KVYL---ST FNVWREILSNTT 39 $::_{:}^{*} \quad{ }^{*}: . \quad:$

RS IDLSAMYWNLLGEEDRKVY-----TDAEMTKFGADRGKNLLLALKEAAIRG-----VK 150 SSLD IASFYWTLTNNDTH-----------TQEPSAQQGEEVLRQLQT LAPKG-----VN 160 TSLDIASFYWTMKAEDTP----------GVSDNSTMPGEDVEARLLANGNGGSRSPRIK 169 LSLD I IAOYWOLNAHPDDPLSGDYGYSKADMHKFGAHEGFDVYRALENAADRN------IS 121 KTLDISSFYWSLS---------------DEVGTNFGTT I LNEIVQLPKRG-----VR 76

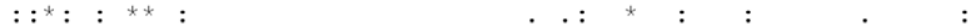

IRVLTAKONVETGEIDEAAEMSCGSLPSEVOMLVNAAKKKVEVRCWSGPEWYGSGI LHOK 210 VRIAVSKPSGPQPQADLQALLQSG---------------AQVRMVDMQKLTH-GVLHTK 203 LRIAQSEPSTASPSLNTKLLESAGA------------AEVVSISFPKYFGSGVLHTK 214 IRLLQHSGVYPDYTKEPSDLASGRP-------------NVENVTLLLGEWWGSGIVHAK 167 VRIAVNKSN--KPLNDVETLQMAG----------------VEVRYIDITNILG-GVLHTK 117 $:{ }^{\star}: \quad . \quad$ : $\quad . \quad$ :

IWIFDDSHVYVGSANMDWKSLAOVMEVGVVMEDLSPT SNVIODMKRLYETWWMFASPELL 270 FWVVDQTHFYLGSANMDWRSLTQVKELGVVMYNCS---CLARDLTKIFEAYWELGQAGSS 260 LWVVDDRHFYLGSANMDWRALTQVKEMGVLVQNCP---NLAHDVAKI EEEYWYLGNSESS 271 VWI SDSRDVYIGSANNDWKSLTQVKEVGIYLVDCP---SIARQVE IYYNNLWKLASLNVS 224 FWISDNTH I YLGSANMDWRSLTQVKELGIAI FNNR---NLAADLTQI FEVYWYLGVN--N 172

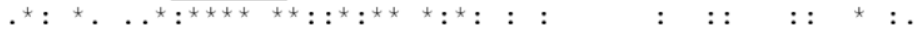

PAKTDRYFSERFQ-HELQVPKWSLYLPTEKRNVDPFVKAGLSALGN ISHQLQTTFNTPLS 329

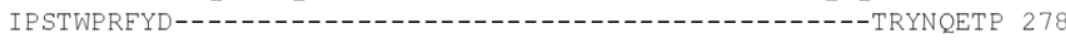

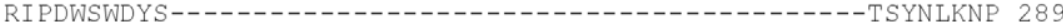
AYTTTVWDQQWQINRQVPCWSHFLT PRERCRSPLPRYVAVPHVVGYPTLSDPRMFKTPIQ 284

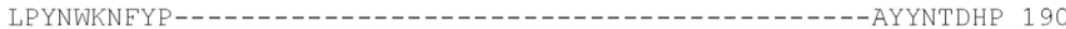
$:$ :

GN-DTERGAETADMFVAAAPLEATAAHSRAFDEDALVYT IRSAKS--FIGLSVMDFVPFS 386 ME-ICLNG-T PALAYLASAPPPLCPSG-RTPDLKALLNVVDNARS--FIYVAVMNYLPTL 333 MO-LSVNTNT SMEGELSSSPPPLSAYG-RTNDLDAILNT INTAIT--YVNIALMDYYPLI 345 TPGHNCST SKPQSSCLSFAPPELSFGK-HQADEQAWVDT IKSVGTGATVRINSMDWLGQS 343 LS-MNVSG-VPHSVEIASAPQQLCTME-RTNDLTALLSCIRNASK--FVYVSVMNFIP I 245

$$
::{ }^{*} \quad{ }^{*} *: \quad: \ldots . \quad: \quad{ }^{*}: \text { : }
$$

MYTPG-PLHWPALTDALLAGVYSKPGLQVCLLISQWQHTSTQMLKALATLKKQADLCQHT 445 EFSHP-HRFWPA IDDGLRRATYER-GVKVRLLISCWGHSEP SMRAFLLSLAALRDNHTHS 391 IYEKK-RSYWPF IDDALRKAAVER-GVAVKLLISWWKHSDPREDRELRSLQDLASKEEKI 403 QYMQQ-TVYWSSLSSAVSEVVFSK-HAKVKI LVAYWAHF INNTDQYLKSLLYSNVLCYSS 401 YSKA GN ILEWPY IEDELRRTAIDR-KVSVKLLISCWQRSSE IMRNELRS I AMLKS--KN I 302

$$
{ }^{\star} .: \text { : : . . : * : }{ }^{\star}: \text { : } * \text { : }
$$

HARCSG-RLEIKIFRVPGWONTTSSAR----TKAVWP SYTRVNHAKYIVTDTRVNVGT SN 500 DI------0VKLFVVPADEAQARI P-----------YARVNHNKYMVTERATYIGTSN 432 DI-------QIRRE IVPT DASQEKI P-----------EGRVNHNKYMVTDRVAYIGTSN 444 KYNKCSGKVE IKYYKVPGENLTGPA I HNGTSTGNIYPGETRVNHGKYAVSDVRAHIGT SN 461 DI-------EVKLFIVP--DADPPIP----------YSRVNHAKYMVTDKTTYIGTSN 341 . $::: * * \quad: * * * * * *::$ : : $: * * *$

MEWGYFYTTAGASVNTNH-------EPTRKALENVFKRNWNSSYAKSLEEIVSAES------ 549 WSGNYFTETAGT SLLVTQ----NGRGGLRSQLEAIFLRDWDSPYSHDLDTSADSVGNACRLL 490 WSGDYFTDTAGI GLVLGET FETETTNTVRSDLRNVFERDWNSKYATPLK------------- 493 LVWDYFYSTAGVSFGTYN-------PAIVSQLQEI FDADWNSPYAVPVEPLEEGQFHSSR-- 514 WT GNYFTDTCGTSINITP----DDGLGLRQQLEDI FMRDWNSKYSYELYDTSPTKR--CRLL 395

$$
.{ }^{*}{ }^{*} .{ }^{*} \ldots \quad .{ }^{*} .:{ }^{*} \quad:{ }^{*}:{ }^{*}: \quad:
$$

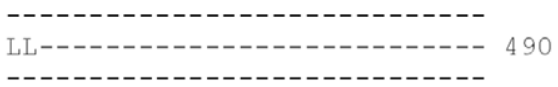

-

LLKNMKQCTNDIYSDEIQPEKEIPEYSLE 424 
Figure 5. Phylogram of $P$. infestans PLD-likes and type B sPLD-likes and homologs in various organisms. The consensus minimal evolution tree constructed from the amino acid sequences is shown. For accession numbers of the $P$. infestans sequences see Table 1 . Other sequences that were all selected by Blast searches are from: Arabidopsis (accession nr. NP_188194 for AtPLD $\alpha 1$, NP_175666 for AtPLD $\alpha 2$ and NP_197919 for AtPLD\&3), Frankia alni (P_711983), Janibacter (ZP_00995229), Kineococcus radiotolerans (YP_001361943), Kribbella flavida (YP_003383471), Mycobacterium smegmatis (YP_884788), Oceanibulbus indolifex (ZP_02154842), Saccharopolyspora erythraea (YP_001106428), Streptomyces ambofaciens (CAJ89461), Streptomyces pristinaespiralis (YP_002197876) and Streptosporangium roseum (YP_003339462). doi:10.1371/journal.pone.0017767.g005

scaffold_64 and P. ramorum scaffold_112 suggesting another duplication event. Alternatively, scaffold_228 which is only 184 $\mathrm{kb}$ in size, might in reality be part of scaffold_18. For genes flanking sPLD-like-11 and -12 homologs were found in the other two species but not in regions harbouring sPLD-like-B genes. Based on the phylogeny and the synteny it seems plausible that the two $P$. infestans specific sPLD-like-B clades arose by gene duplication after emergence of the species infestans. Moreover, since $P$. sojae and $P$. ramorum are more at the base of the Phytophthora phylogeny than $P$. infestans the absence of $P$. infestans orthologs in some subclades is probably due to gene loss.

\section{sPLD-like-A represents an independent peak in PLD evolution}

Phytophthora sPLD-like-A is quite divergent from other PLDs. The closest relatives are found in plants while more distant SPLDlike-A sequences are widespread in metazoan, viruses and prokaryotes. This suggests they are all descendants of an ancient gene (Figure 3; Table 3). In contrast, the sPLD-likes-Bs and PLD-likes are most analogous to PLD-like sequences derived from actinomycetes (Figure 4). Representative sPLD-like-A homologs were further analysed for potential characteristics (Table 3) and some clade representatives were aligned (Figure 5). It was noted that the prediction of the SP for Phytophthora orthologs is indecisive and hardly discriminates between a SP or a signal anchor (SA). Signal anchors are found in proteins that are inserted but not cleaved in the ER. sPLD-like-A homologs from plants and Dictyostelium have an obvious SP with an HMM score higher than 0.98. In contrast, a SA was predicted for many other sPLD-like-As, including all mammalian derived homologs (HMM score $>0.98$ ). Some, including those of Caenorhabditis elegans, Drosophila erecta and virus derived sequences, have neither a SP nor a SA (Table 3).

All sPLD-likes-As have a correct HKD1 except for Physcomitrella patens. For HKD2, a substitution is observed in nearly all mammalian and in the Dictyostelium homolog. The "VGSANMD" motif adjacent to the HKDl motif is well conserved among all. Phytophthora sPLD-like-As are highly homologous $(>75 \%)$ but with sPLD-like-As from other organisms the homology is much lower (Figure 5). The conserved regions mainly cover the HKD1 and HKD2 motifs and surrounding regions.

\section{Extracellular PLD activity}

The finding that PLDs in two of the subfamilies have putative signal peptides urged us to validate if $P$. infestans secretes PLDs. First, the expression of the various PLD genes was analysed using $P$. infestans EST depositories [13] and Nimblegen data [14]. ESTs were identified (Table 1) for PXPH-PLD, PXTM-PLD, TM-PLD, sPLD-like-1, sPLD-like-12 and PLD-like-1. Most ESTs are derived from mycelial libraries which is in agreement with the Nimblegen expression profiles (Figure S1). The mycelial tissue was therefore tested as the source for extracellular PLD activity. A mix of metabolically labelled plant phospholipids was presented as substrate to cell free $P$. infestans extracellular medium. The reaction was performed in the presence of a primary alcohol. PLDs have the unique capability to transfer a phosphatidate intermediate to short-chain primary alcohols (acting as substitute for water) resulting in the formation of phosphatidylalcohols [15]. These transphosphatidylation products are easily detectable by thin layer chromatography (TLC) due to their metabolic stability and unique migration properties. Incubation of extracellular medium of $P$. infestans mycelial cultures with the metabolically labelled phospholipids in the presence of $2 \%$ propanol resulted in the production of both PA and phosphatidylpropanol (PPro) whereas in the control V8 medium no PLD activity was detected. Increase in PA and appearance of the non-pre-existing PPro was observed for all $P$. infestans strains tested (Figure 6) and this points to a ubiquitous presence of extracellular PLD activity. PA and PPro levels varied per strain which probably reflects differences in growth rate, viability of the mycelium, or variation in the amount of secreted activity among strains. Transphosphatidylation was already observed at the lowest propanol concentration tested $(0.1 \%$; Figure 6 , inset).

To exclude that release of intracellular PLDs from dead or dying cells causes the observed activity, V8 medium of a flooded plate was carefully removed, fresh medium was added and after overnight incubation the extracellular medium was again tested for PLD activity. In the "fresh" extracellular medium PLD activity appeared to be even higher than in the extracellular medium prior

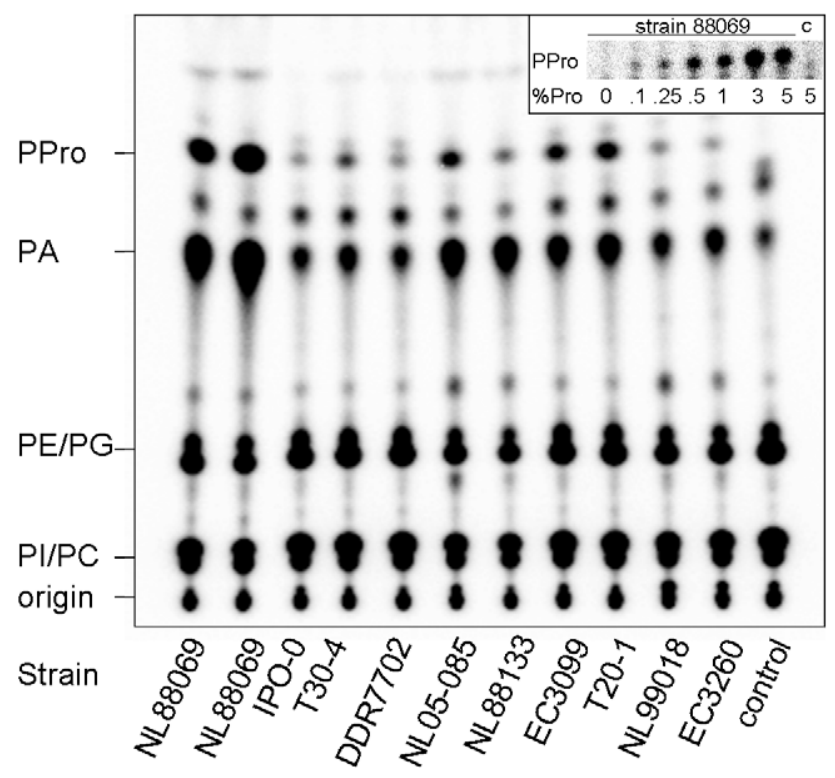

Figure 6. Profiles of plant phospholipids exposed to $P$. infestans extracellular medium reveals PLD activity. Metabotically labelled phospholipids were isolated from tobacco suspension cell culture, sonicated into vesicles, mixed with extracelllular medium collected from various $P$. infestans strains and incubated for $60 \mathrm{~min}$ in the presence of a primary alcohol ( $2 \%$ propanol). Lipids were (re)extracted, separated by TLC and visualized by phosphoimaging. As control, vesicles were treated with V8 medium. The origin, phosphatidylinositol (PI), phosphatidylcholine $(P C)$, phosphatidylethanolamine $(P E)$, phosphatidylglycerol $(P G)$, phosphatidic acid (PA) and phosphatidylpropanol (PPro) are indicated. Inset, control medium (c) or extracellular medium (strain 88069) were incubated in the presence of propanol. \%Pro indicates the final propanol concentration.

doi:10.1371/journal.pone.0017767.g006 
to the replacement, demonstrating that the extracellular PLD activity is due to active release of PLD by living cells (Figure S2).

\section{Discussion}

Eighteen PLD genes were identified in the genome of $P$. infestans and this correlates with findings in $P$. sojae and P. ramorum [4]. It clearly exceeds the number of PLD genes in yeasts, mammalians, and even plants. Also the number of PLD subfamilies in Phytophthora is staggering: six subfamilies including two distinct potentially secreted sPLD-like subfamilies, type A and B. Like many plant pathogens Phytophthora species have large secretomes [14], anticipating potential functions in pathogenicity. Our finding that $P$. infestans secretes PLD activity in the medium suggests that Phytophthora exploits PLDs to modify host tissues and as such, PLDs may function in pathogenicity.

Phytophthora PXPH-PLD and PXTM-PLD are closely related to canonical PXPH-PLDs as illustrated by conserved catalytic and regulatory domains with the exception of the transmembrane domains in PXTM-PLD. A preliminary functional analysis revealed that homozygous PXTM-PLD knock-out mutants show aberrant growth behaviour [16]. TM-PLD lacks homology with any other protein outside Phytophthora. Within Phytophthora species TM-PLD is highly conserved suggesting that this protein has a function in these organisms although not necessarily as a PLD.

The sPLD-like-Bs and PLD-likes have all regulatory domains typical for PLDs but lack the lipid binding domains and the DRY motif. Most possess an altered HKDl motif lacking aspartate. Nevertheless, the motif might still be able to participate in a catalytic reaction. Attempts to express the genes in E. coli were unsuccessful. The transformation rate was low and in all viable transformants the constructs showed frameshifts or point mutations leading to inactive proteins (unpublished observations). The abundance of sPLD-like-B isoforms suggests that they have a prominent function.

In contrast to eleven sPLD-like-Bs, $P$. infestans has only one sPLD-like-A which, unlike sPLD-like-Bs, has an inconclusive prediction for its signal peptide. sPLD-like-A homologs exist outside oomycetes. The homology, however, is mostly restricted to the catalytic motifs and there is no uniform signal peptide prediction. The latter could point to different destinations of the various sPLD-like-As, in or outside the cell. Unlike the metazoan homologs, the plant homologs have an obvious signal peptide. This might be essential to cross cell walls and reach membranes in adjacent cells. Like plants, Phytophthora has cell walls so for Phytophthora sPLD-like-A one could argue in favour of a signal peptide for rather than a signal anchor. However, this needs further experimentation.

The large number of sPLD-likes suggests that Phytophthora secretes PLD activity. Since most sPLD-likes have a modified HKD motif, the substrate specificity is unknown and unanticipated activities could be encountered. Potential PLD activity monitoring problems, due to substrate specificity, phospholipid composition and ratio, alternative phospholipase and kinase activities and buffer preferences were circumvented by exploring a novel in vitro approach based on labelled plant phospholipids. We demonstrated that all tested $P$. infestans strains secrete PLD activity although the identity of the active enzyme remains to be established. The observed differences in PLD activity among strains probably reflects variations in growth rate, viability and the

\section{References}

1. Wang X, Devaiah SP, Zhang W, Welti R (2006) Signaling functions of phosphatidic acid. Prog Lipid Res 45: 250-278. amount of enzyme(s) secreted. Analysis of similar samples by an alkaline TLC system revealed that PtdCho and PtdGro are the main substrates (data not shown). The PLD activity was capable to transphosphatidylate at low alcohol concentrations as expected for common PLDs [2]. This novel in vitro assay could be a first-class tool to dissect the biochemical characteristics of the PLD activity and to identify the enzyme(s) responsible.

Phytophthora is a hemibiotrophic plant pathogen and as such it is conceivable that secreted PLDs are utilized to function as generators of PA at the outside layer of host cell plasma membrane. PA has been characterized as a multifunctional phospholipid with direct or indirect impact on many cellular processes $[1,17]$. In mammalian cells, exogenous added PLD activates G-protein-coupled receptors thereby mimicking hormones and growth factors [1]. Adding exogenous PA to P. infestans zoospores triggers encystment [9] whereas exogenous PA addition to plant cell-suspension culture results in MAPK activation, actin cytoskeleton rearrangements, reactive oxygen species generation, chlorosis, cell death responses [1,8] and stimulation of secretion [17]. Ergo, if Phytophthora PLDs initiate PA production at the plant membrane several cellular processes may be activated that influence the infection process.

\section{Supporting Information}

Figure S1 Nimblegen microarray data for Phytophthora infestans PLD genes. Each bar represents the average of two individual hybridisations. Samples were taken from $P$. infestans mycelium (strain T30-4) on various agar media (Pea agar, V8 agar and RS agar) or from infected potato leaves, 2-5 days postinoculation (DPI). Nimblegen microarray data are available in GEO under accession number GSE14480 [14].

(TIF)

Figure S2 PLD activity is continuously released into fresh medium. Metabolically labeled phospholipids were incubated for $60 \mathrm{~min}$ in the presence of $2 \%$ propanol with fresh control medium (c), extracellular medium obtained by flooding $\left(1^{\mathrm{e}}\right)$ and refreshed extracellular medium $\left(2^{\mathrm{e}}\right)$ of $P$. infestans strain 88069. Lipids were extracted, separated by TLC and visualized by phosphoimaging.

(TIF)

Table S1 Amino acid identity between $P$. infestans sPLD-likes. The comparison was performed using Vector NTI and the results are presented as percentage (\%) identity.

(DOC)

\section{Acknowledgments}

We are grateful to Matthieu Joosten for providing the plant cell suspension cultures and the Laboratory of Molecular Biology of Wageningen University for giving access to the Storm scanner. We thank our colleagues for many fruitful discussions.

\section{Author Contributions}

Conceived and designed the experiments: HM FG. Performed the experiments: HM HH. Analyzed the data: HM. Wrote the paper: HM FG. 
3. Li G, Lin F, Xue HW (2007) Genome-wide analysis of the phospholipase D family in Oryza sativa and functional characterization of PLD $\beta 1$ in seed germination. Cell Res 17: 881-894.

4. Meijer HJG, Govers F (2006) Genomewide analysis of phospholipid signaling genes in Phytophthora spp.: novelties and a missing link. Mol Plant Microb Inter 19: 1337-1347.

5. Tamura K, Dudley J, Nei M, Kumar S (2007) MEGA4: Molecular Evolutionary Genetics Analysis (MEGA) software version 4.0. Mol Biol Evol 24: 15961599 .

6. Meijer HJG, Latijnhouwers M, Ligterink W, Govers F (2005) A transmembrane phospholipase D in Phytophthora; a novel PLD subfamily. Gene 350: 173-182.

7. Caten CE, Jinks JL (1968) Spontaneous variability of single isolates of Phytophthora infestans. I. Cultural variation. Can J Bot 46: 329-348.

8. de Jong CF, Laxalt AM, Bargmann BO, de Wit PJGM, Joosten MHAJ, et al. (2004) Phosphatidic acid accumulation is an early response in the Cf-4/Avr4 interaction. Plant J 39: 1-12.

9. Latijnhouwers M, Munnik T, Govers F (2002) Phospholipase D in Phytophthora infestans and its role in zoospore encystment. Mol Plant Microb Interact 15: 939-946.

10. Chae YC, Lee S, Lee HY, Heo K, Kim JH, et al. (2005) Inhibition of muscarinic receptor-linked phospholipase D activation by association with tubulin. J Biol Chem 280: 3723-3730.
11. Ho AYY, Day DA, Brown MH, Marc J (2009) Arabidopsis phospholipase D $\delta$ as an initiator of cytoskeleton-mediated signalling to fundamental cellular processes. Funct Plant Biol 36: 190-198.

12. Pleskot R, Potocký M, Pejchar P, Linek J, Bezvoda R, et al. (2010) Mutual regulation of plant phospholipase $\mathrm{D}$ and the actin cytoskeleton. Plant J 62 : 494-507.

13. Randall TA, Dwyer RA, Huitema E, Beyer K, Cvitanich C, et al. (2005) Largescale gene discovery in the oomycete Phytophthora infestans reveals likely components of phytopathogenicity shared with true fungi. Mol Plant Microb Inter 18: 229-243.

14. Haas BJ, Kamoun S, Zody MC, Jiang RHY, Handsaker RE, et al. (2009) Genome sequence and analysis of the Irish potato famine pathogen Phytophthora infestans. Nature 461: 393-398.

15. Munnik T, Arisz SA, De Vrije T, Musgrave A (1995) G protein activation stimulates phospholipase D signaling in plants. Plant Cell 7: 2197-2210.

16. Lamour KH, Finley L, Hurtado-Gonzales O, Gobena D, Tierney M, et al. (2006) Targeted gene mutation in Phytophthora spp. Mol Plant Microb Inter 19: 1359-1367.

17. Madrid E, Corchete P (2010) Silymarin secretion and its elicitation by methyl jasmonate in cell cultures of Silybum marianum is mediated by phospholipase D-phosphatidic acid. J Exp Bot 61: 747-754 